\title{
NEUROCIÊNCIA, PODER E SUBJETIVIDADE
}

Vanessa Ananias Malacrida

Universidade Estadual Paulista - UNESP, Programa de Pós Graduação em Educação, Presidente Prudente, SP. E-mail: vamalacrida@bol.com.br

\section{RESUMO}

Este artigo se propõe a tomar como foco de análise alguns fenômenos atuais e as influências relacionadas ao desenvolvimento da neurociência à luz do conceito de biopolítica de Foucault considerando a prática de curar para governar a vida. Enfatiza o impacto da neurociência no contexto atual e a busca por maior desempenho e melhor performance na produção. Visa promover a reflexão sobre as formas de subjetividade reducionistas da contemporaneidade considerando a importância desta compreensão por parte dos educadores. Partindo da visão crítica de Han (2017) das sociabilidades do século XXI contribui para a reflexão sobre os impactos e consequências culturais, existenciais e sociais da hiperatividade, hipermobilidade atuais, da comunicação generalizada, da superinformação e da hipermidiatização na condição humana. $O$ interesse pelo tema abordado surgiu no decorrer de uma disciplina da pós-graduação do doutorado em educação. Trata-se de pesquisa qualitativa em estágio inicial que aponta a importância da abordagem destas questões na formação continuada.

Palavras-chave: Biopolítica, neurociência, subjetividade reducionista, sujeito cerebral, cansaço.

\section{NEUROSCIENCE, POWER AND SUBJECTIVITY}

\begin{abstract}
This paper proposes to take as focus of analysis some current phenomena and the influences related to the development of neuroscience in light of Foucault's concept of biopolitics considering the practice of healing to govern life. It emphasizes the impact of neuroscience in the current context and the search for greater performance and better performance in production. It aims to promote reflection on the contemporary reductionist forms of subjectivity, considering the importance of this understanding on the part of educators. Based on Han's (2017) critical view of the sociabilities of the 21st century, it contributes to the reflection on the cultural, existential and social impacts and consequences of hyperactivity, current hypermobility, generalized communication, superinformation and hypermidiatization in the human condition. Interest in the topic was raised in the course of a postgraduate discipline of the doctorate in education. This is an initial qualitative research that points out the importance of addressing these issues in continuing education.
\end{abstract}

Keywords: Biopolitics, neuroscience, reductionist subjectivity, cerebral subject, fatigue. 


\section{INTRODUÇÃO}

As implicações das transformações culturais e comunicacionais do nosso tempo, as novas configurações do trabalho são características da sociedade atual denominada por Han (2017) como "sociedade do cansaço". Han afirma que cada época possui suas enfermidades fundamentais, a partir da "leitura patológica" entre diferentes épocas, aponta, a bacteriológica, que chegou ao fim com a descoberta dos antibióticos, a viral, controlada pelas técnicas imunológicas e a neuronal que define a época atual desde o início do século. Assim:

Doenças como depressão, transtorno de défict de atenção com síndrome de hiperatividade (Tdah), transtorno de personalidade limítrofe (TPL) ou a síndrome de Burnout (SB) determinam a paisagem patológica do começo do século XXI. Não são mais infecções, mas enfartos, provocados não pela negatividade de algo imunologicamente diverso, mas pelo excesso de positividade. Assim, eles escapam a qualquer técnica imunológica que tem a função de afastar a negatividade daquilo que é estranho. (HAN, 2017, p.7-8)

A visão crítica de Han (2017) das sociabilidades do século XXI permite a reflexão sobre as consequências culturais, existenciais e sociais da hiperatividade e hipermobilidade atuais, da comunicação generalizada e da superinformação nos permite observar a violência da positividade, ligada a vários excessos, particularmente a uma sobrecarga da produtividade e dos estímulos midiáticos. Sendo resultado da superprodução, superdesempenho ou supercomunicação já não é mais viral, o autor atenta para o fato de que a "imunologia não assegura mais nenhum a acesso a ela", pois a violência da positividade não tem negatividade, é saturante e exaustiva, diferente da violência da negatividade que é privativa e excludente. A violência neuronal é considerada como uma violência sistêmica, tanto a depressão, como o TDAH e a síndrome de Burnout (SB) "apontam para um excesso de positividade. A SB é uma queima do eu por superaquecimento, devido a um excesso de igual" Han (2017). As pessoas adoecem devido à violência da positividade característica desta sociedade atual.

Partindo da indagação sobre qual o impacto desta realidade na sociedade e na educação atual, este artigo se propõe a instigar a reflexão sobre a biopolítica e o poder de curar para governar para a vida enfatizando o impacto da neurociência neste contexto e a busca atual por maior desempenho e melhor performance na produção. Objetiva-se ainda promover a reflexão sobre as formas de subjetividade reducionistas da contemporaneidade que educadores precisam compreender por estar inserido neste contexto para repensar práticas e posturas.

\section{METODOLOGIA}

O interesse pelo tema se deu no curso da disciplina do programa de pós-graduação da UNESP- FCT de Presidente Prudente. A pesquisa qualitativa em estágio inicial ainda se encontra na fase de pesquisa bibliográfica não contando com tabulação de dados até então.

\section{RSULTADOS}

Os resultados obtidos apontam para a necessidade da abordagem destas questões na formação continuada dos educadores pelo fato de que a escola é produtora de subjetividades para que se desenvolva reflexões criticas a respeito das relações de poder, do impacto da neurocultura e compreensão de fatores como a patologização e a medicamentalização de crianças visando sanar sintomas baseando-se na subjetividade reducionista desconsiderando o contexto em que se apresentam. Cabe lembrar que muitas vezes o professor participa por meio de emissão de relatórios de observação sobre o aluno no processo de diagnóstico médico e laudamento. 


\section{NEUROCULTURA, A SUBJETIVIDADE REDUCIONISTA, MEDICAMENTALIZAÇÃO}

A sociedade atual vive o crescente impacto das neurociências e o surgimento da neurocultura que deu início também a forma de subjetividade reducionista, o "sujeito cerebral" que segundo Ortega (2009), dá lugar a aparição de prática de si cerebrais, isto é, praticas de como agir sobre o cérebro para maximizar sua performance, trata-se do fenômeno denominado "neuroascese ou autoajuda cerebral". Outros autores apontam características relacionadas. Guarido (2010) ressalta que o discurso contemporâneo é povoado pela biologização da vida e a medicina como representante do discurso cientifico, tem divulgado constantemente na mídia os resultados das pesquisas em neurologia e estudos genéticos, um dos problemas relacionados a isto é a proliferação de simplificações e mitificações. Outro ponto indicado por Guarido é a medicalização de crianças acompanhada pela desconsideração do contexto em que vivem e as complexas manifestações singulares de cada sujeito:

(...) atualmente uma multiplicidade de diagnósticos psicopatológicos e de terapêuticas que tendem simplificar as determinações dos sofrimentos ocorridos na infância. O que conhecemos como resultado deste tipo de prática é que um número cada vez maior de crianças em idade cada vez mais precoce é medicado de forma a tentar sanar sintomas das crianças, sem considerar o contexto na qual se apresentam; não levando em conta também as complexas manifestações singulares de cada sujeito. Assim, no lugar de considerar um psiquismo em estruturação, supõe-se um déficit neurológico. (GUARIDO, 2010, p.29)

O disposto acima nos alerta para a necessidade de compreensão por parte dos educadores desta neurocultura e suas consequências, uma vez que sabemos (devido a experiência cotidiana nas escolas) que muitos destes diagnósticos psicopatológicos não são emitidos, sem antes haver sido solicitado aos professores, relatórios sobre estas crianças. Claro que sabemos que há casos onde realmente os medicamentos são necessários, também se sabe que a neurociência é uma ciência com contribuições reconhecidamente importantes, o problema apontado aqui não é os avanços da neurociência, mas a medicalização baseada no reducionismo cerebral desconsiderando o sujeito como um todo e sua complexidade.

Conforme Guarido (2010) "medicalizar o fenômeno teve, tradicionalmente, o sentido geral de reduzir as problemáticas sociopolíticas a questões individuais. (...) medicalizar um fenômeno ou acontecimento teve por consequência patologizá-lo". A formação continuada com uma abordagem filosófica como forma de contribuir para a compreensão supramencionada é fundamental, dado que a permeabilidade da escola ao discurso médico e psicológico é histórica e a:

\footnotetext{
"hegemonia do discurso sobre o organismo, sobre seus aspectos funcionais reduz a consideração da dimensão simbólica da subjetividade, como efeito disso, poderíamos ressaltar uma retirada da possibilidade de atuação dos sujeitos sobre o que lhes acontece, já que os problemas e condições de aprendizado das crianças estariam dados pelo funcionamento cerebral e não pela interferência de um outro na sua condição de estruturação e desenvolvimento." (GUARIDO, 2010, p.37)
}

Como aponta a autora corremos o risco de um esvaziamento do ato educativo e da densidade da experiência humana desconsiderando o todo complexo do aluno e da pessoa humana, considerando apenas os aspectos cerebrais. É fundamental a compreensão pelos atores sociais educacionais sobre a realidade neste contexto no qual o ser humano se reduz ao seu cérebro, e a escola, mais que produtora de ideologias é produtora de subjetividades, e assim corremos o risco de reproduzir subjetividades reducionistas se estivermos alienados do que está acontecendo. 
Foucault (1999) denuncia as formas de poder, da soberania do poder sobre a morte na era clássica e disciplina do corpo no século XVII, ao poder político de gerir a vida na modernidade, no século XVIII o controle dirigido às populações. No século XIX o biopoder emerge das duas formas anteriores, sob o pretexto de bem estar da população, a ênfase na medicina e na medicalização da vida. Desde o final do século XVIII a medicina assume função higienista. Ortega (2009) salienta que o progresso das tecnologias neurocientíficas sua popularização pela mídia, tem dado uma nova conotação ao cérebro que definem o que é ser alguém, reduzindo a pessoa humana ao cérebro, a partir da noção de sujeito cerebral que implica formas de subjetivação enquanto sujeitos cerebrais. Segundo Ortega e Vidal (2007) é chamado "sujeito cerebral" a "figura antropológica que incorpora a ideia de que o ser humano é essencialmente reduzível a seu cérebro", caracterizada pela propriedade da "cerebralidade", o "ser" ao invés de apenas "ter" um cérebro.

(...) considerar que os seres humanos são seus cérebros tem consequências sociais significativas, nas áreas da lei e da medicina, por exemplo. E nem a lei, nem a medicina, e nem mesmo as próprias neurociências, são independentes de representações, valores, esperanças e práticas cujas origens estão fora de suas fronteiras profissionais. Desde o século XIX, o cérebro tem funcionado como um mediador e como uma superfície de projeção, mas, agora, ele se tornou um agente social. É por isso que, em nossa pesquisa, abordamos as neurociências como se incrustadas no tecido social, mais do que meramente como tendo "implicações sociais" ou um "impacto" na sociedade. (Ortega, 2007 p.258)

Mais do que um impacto, ou meras implicações a neurociência é considerada por Ortega como "incrustada no tecido social", as consequências sociais por conta deste fenômeno são significativas em diversas áreas. A pesquisa relacionada a este artigo, ainda em estágio inicial, visa levantar e compreender melhor estas consequências e contribuir com percepção das relações de poder sobre a ação docente e o papel da escola. É necessária a desalienação de atores sociais escolares do nosso tempo sobre as formas de governamentalidade atuais e sobre a violência da positividade da qual, sem perceber ou compreender, somos vitimas e agressores ao mesmo tempo, colaborando assim para a reprodução de subjetividades das quais, muitas vezes, desconhecemos. Han (2017) descreve a evolução da sociedade de produção para uma sociedade de "doping" tal como o positivamente chamado neuroenhancement, ou neuro reforço na busca da maximização produtiva induz a transformação do corpo e do ser humano numa "máquina de produção" o que produz um "cansaço alienante".

Eremberg (2010) nos leva a refletir sobre o culto da performance que é caracterizado pela confluência de 3 discursos, o esportivo, o do consumo e o empresarial, levando respectivamente a competitividade, consumismo e a adesão ao discurso empresarial que leva a reconversão da sociedade ao culto da performance, cujo modelo ideal de conduta passa pelo ato de empreender, ser bem sucedido, assumir riscos. Este regime de excelência segundo o autor pode ter consequências negativas como a corrosão de caráter, rupturas com as formas tradicionais de sociabilidades e laços sociais, impacto direto sobre o humor e regime econômico que incentiva o consumismo. Envolve mudanças no mundo do trabalho, sendo que, o capital humano aumenta o valor quanto melhor for sua gestão, a realização pessoal exige permanente superação, não restando outra opção senão entrar no jogo concorrencial pautado pela performance. Não mais a obediência é causa dos males psíquicos, mas a pressão por desempenho, neste contexto o homem explora a si mesmo, é agressor e vitima ao mesmo tempo. O sujeito do desempenho entra em guerra consigo mesmo, autoacusação destrutiva e autoagressão. A sobrecarga de trabalho, a atenção em varias tarefas ao mesmo tempo e o cansaço é um sintoma de nossa época.

O liberalismo iniciado no século XVIII deslocou-se para o neoliberalismo a partir de meados do século XX. Sabemos que no liberalismo a liberdade de mercado era conhecida como algo 
natural, no neoliberalismo a liberdade deve ser continuamente produzida e exercitada sob a forma de competição, este é o ponto que ira despertar maior interesse na escola no neoliberalismo, segundo Veiga Neto (2011). Década de 1970, Foucault desenvolveu nos cursos do Collêge de France insights que, nos levam a, ao invés de compreendermos o liberalismo e o neoliberalismo como "ideologias de sustentação e justificação do capitalismo e do capitalismo avançado (respectivamente), é mais produtivo compreendê-los como modo de vida, como ethos, como maneira de ser e de estar no mundo".

Assim, a "escola passa a ser entendida como uma instituição encarregada de fabricar novas subjetividades" e não apenas como um lugar onde se ensinam e se aprendem ideologias. 0 trabalho atualmente exige um sujeito flexível, capaz de ser realocado em funções diversas. Na economia capitalista a fábrica situa-se do lado da modernidade sólida, a empresa, predominante hoje, situa-se do lado da modernidade líquida, funcionando com o número de trabalhadores drasticamente reduzido, passamos da fábrica para a empresa enquanto modelo de organização, a subjetividade do operário é transformada, dotando-o de poder de gestão das informações e de tomada de decisões. A reorganização do trabalho, a partir do modelo do trabalho imaterial, traz mudanças na maneira de controlar a produtividade do trabalhador, da vigilância sobre o corpo e as funções bem definidas da fabrica, dá lugar a organização do trabalho imaterial em que é necessária a comunicação, a cooperação entre cérebros, por uma ação mútua. Por mobilizar principalmente o cérebro, buscando a inovação, a vigilância sobre o corpo perde importância, o controle se desloca do corpo para o cumprimento das metas por meio dos indicadores e da visibilidade, neste contexto o controle recai sobre as almas e não sobre o corpo.

"Reinventa-se a tecnologia celular por meio de um controle acionado a distância através de tecnologias digitais. Essa nova estratégia é colocada em funcionamento, utilizando recursos tecnológicos tais como mensageiros instantâneos e telefones celulares, o que permite alcançar cada um com maior eficácia, sem restrições espaço temporais significativas. Assim, a sociedade de consumidores, em que se desenvolve o capitalismo cognitivo, é uma sociedade do acontecimento. (VEIGA NETO 2011, p.43)

A reinvenção da tecnologia, não só do celular, mas a tecnologia digital em geral, aumentou possibilidades de monitoramento de cada indivíduo com maior eficácia, bem como os sistemas informatizados para acompanhamento de metas atingidas e prazos tornou-se comum, em um tempo marcado pela correria. Vivemos numa cultura do instantâneo, diferente da sociedade dos produtores onde a durabilidade e solidez era a qualidade desejável, a satisfação era adiada, na vontade de garantir segurança em longo prazo, pensando no futuro. Na atual sociedade de consumidores, o que importa é a satisfação imediata dos desejos, "insaciáveis". Não se busca a durabilidade, mas produtos leves, voláteis, descartáveis, "passamos de uma sociedade que se projetava na caderneta de poupança para uma sociedade que se projeta no cartão de crédito", conforme Veiga Neto (2011). Na modernidade líquida, a administração dá lugar à gestão empresarial, não se administra para o futuro, mas na incerteza, a gestão é marcadamente interdisciplinar e flexível, mutável e adaptativa, "enquanto a administração tem seu funcionamento ligado a cenários mais estáveis, (...) a gestão tem maior capacidade de lidar com a instabilidade. (...) com o devir".

No contexto atual é fundamental que educadores tenham consciência das formas de poder e controle. Os dispositivos capazes de atingir cérebros à distância que atingem especialmente a jovens e crianças, disponibilizando um novo repertório de valores e de comportamentos, muitas vezes conflitantes com aqueles que são apresentados nos ambientes escolares. Veiga Neto (2011) citando Lazzarato faz apontamentos comparativos, entre a modernidade e a contemporaneidade, por meio de três comentários. Primeiro, na modernidade "apenas um mundo poderia se efetuar", 
na contemporaneidade "efetuam-se infinitos mundos incompossíveis" os jovens e as crianças hoje transitam por muitos mundos.

O noopoder é extremamente positivo, ativando o desejo e funcionando pelo exemplo. Sua sutileza e ubiquidade o tornam muito forte. Nesse contexto, a escola talvez não apenas esteja deixando de ser uma instituição centralmente disciplinar como, ainda, esteja se transformando num lugar de produção de novas subjetividades. Assim, por exemplo, muitos dos comportamentos que hoje proliferam nas escolas e que são entendidos como indisciplinares talvez estejam encobrindo novas práticas de subjetivação (MORAES, 2008). Ainda que não tenha lançado mão das ferramentas foucaultianas, os resultados empíricos relatados por Costa (2008) que mostram de que maneira elementos do mundo do consumo, da música e da TV fazem-se presentes na escola, inscrevendo-se sobre os corpos infantis parecem corroborar esse primeiro comentário. (VEIGA NETO, 2011, p.48)

O segundo enfoca a transformação na noção de tempo, a escola ainda mantém um forte vínculo com a lógica disciplinar moderna, alinhada à ética de adiamento da satisfação, não foi pensada para ser prazerosa, ou para atender os desejos imediatos das crianças e dos jovens, seu funcionamento era movido pelo pela vontade e pelo esforço, um lugar de trabalho, não prazer, de acordo com Veiga Neto (2011) "um dos grandes ensinamentos era justamente este: dominar o desejo, desenvolver a vontade. A satisfação prevista pela escola disciplinar era adiada para o final do ano, o final do ciclo, o final da infância, a vida adulta, o futuro", o único prazer admissível era o de aprender aquilo que estava sendo ensinado. Com a progressiva entrada das pedagogias psicológicas, ativas e outras congêneres, assistimos a uma reorganização da temporalidade, as teorias e as metodologias que norteiam o trabalho pedagógico, tem buscado mais a satisfação imediata, dando mais importância ao interesse dos alunos, como por exemplo, a pedagogia de projetos, que parte dos interesses dos alunos, "interesses devidamente direcionados, adequadamente produzidos. Afinal, os alunos podem escolher os temas dos projetos, mas sempre nos limites daquilo que a escola determina como aceitável", Veiga Neto (2011). E por falar em interesse:

"A noção de interesse, como nos mostra Foucault, é bastante importante para o liberalismo e permanece no neoliberalismo. A diferença é que, no segundo caso, o interesse é entendido como algo a ser produzido por intervenções sobre o meio. Na pedagogia de projetos, a decisão do tema pode até ficar a cargo dos alunos, mas deve encaixar-se no recorte estabelecido pelo professor. A vinculação dos projetos ao currículo não permite uma escolha assim tão livre, de modo que o interesse da criança é produzido por intervenções do professor. Lembramos o que Lazzarato (2006, p. 101-2) escreve sobre as relações de consumo - e que coincidentemente parece caber muito aqui; para ele, "nossa 'liberdade' é exercida exclusivamente para escolher entre possíveis que outros instituíram e conceberam. Ficamos sem o direito de participar da construção dos mundos, formular problemas e inventar soluções, a não ser no interior de alternativas já estabelecidas". Os projetos de aprendizagem visam transformar o longo prazo (de recebimento da recompensa) em curto prazo, produzindo satisfação imediata. O tempo contínuo da escola disciplinar torna-se assim um tempo pontilhista, marcado pela sucessão de projetos e mais projetos. (Veiga Neto, 2011, p.49).

O terceiro comentário enfoca uma possível articulação entre as transformações do mundo do trabalho e a educação, em um cenário que o conhecimento torna-se ultrapassado quase no mesmo momento em que é produzido. Aprender a aprender é capacidade buscada pelas empresas, que necessita de indivíduos capazes de aprenderem novas capacitações, um "sujeito em permanente processo de aprendizagem, em permanente reconfiguração de si, é o que se estaria pretendendo que a escola formasse (...) aprender a aprender significaria tornar-se empresário de si, colocando-se num processo de gestão" denuncia Veiga Neto (2011), chamado de 
capital humano pelo neoliberalismo, que espera da escola "ensinar essas técnicas de gestão do capital humano para multiplicá-lo".

\section{CONCLUSÃO}

$\mathrm{Na}$ atualidade o neoliberalismo produz a sujeição dos indivíduos. O capital tem se apropriado do nosso tempo e da nossa atenção. O investimento em capital humano, o empresariamento de si, o sujeito do desempenho, a hiperatividade da atenção, superestimulação, a hipercomunicação, hipermobilidade, a superinformação, a hipermidiatização, o protagonismo do cérebro e a emergência do sujeito cerebral, a neuroascese, processos de produção de vida regidos pelo tempo acelerado, visam à maximização da produção. A cultura do instantâneo, a aceleração do tempo é o traço característico da sociedade contemporânea e leva a perda de controle do nosso próprio tempo, do nosso próprio corpo, como seres despossuídos de si mesmo. O fruto disso tudo é o cansaço alienante, a autoacusação destrutiva e também a síndrome de burnout. A subjetividade reducionista desconsidera o todo complexo de cada indivíduo. A medicamentalização reduz as problemáticas sociopolíticas à questões individuais, ou seja, patologiza.

As discussões dos projetos políticos pedagógicos e curriculares necessitam abranger estas discussões, educadores precisam compreender as relações de poder e o efeito da sujeição dos indivíduos. Pensar a sociedade que temos e a sociedade que queremos envolve compreender a realidade atual, a formação continuada de educadores precisam discutir essas questões, para repensar práticas e posturas e ter clareza de qual sociedade se quer formar, mas para tanto é preciso ter clareza da realidade na qual está inserido e das consequências de cada ação. Há dispositivos capazes de atingir cérebros à distância, especialmente a jovens e crianças, que disponibilizam repertório de valores e de comportamentos, conflitantes, portanto a escola concorre com esses dispositivos, é preciso pensar como utiliza-los a favor da educação. O que precisamos inovar na educação? O neoliberalismo espera que a escola forme indivíduos capazes de aprenderem novas capacitações, em permanente reconfiguração de si, empresários de si e a escola o que pretende? Precisamos refletir sobre a sociedade atual e aquela que queremos construir por meio da educação, o que a escola pretende por meio de seus agentes, nós educadores, sabemos o que queremos e suas consequências sociais, culturais e econômicas? Precisamos pensar sobre o que fazer diante do contexto apresentado, e quais subjetividades estão sendo produzidas na escola.

\section{REFERÊNCIAS}

EHRENBERG, Alain. O culto da performance. Da aventura empreendedora à depressão nervosa. Aparecida, SP: Letras \& Letras, 2010.

FOUCAULT, Michel. Aula de 14 de março de 1979. In: Nascimento da biopolítica. São Paulo Martins Fontes, 2008.

GUARIDO, Renata. A biologização da vida e algumas implicações do discurso médico sobre a educação. Conselho Regional de Psicologia, SP. (Org.). São Paulo Casa do Psicólogo, 2011.

HAN, Buyng-Chul. Sociedade do cansaço. Petrópolis, RJ: Vozes, 2015.

ORTEGA, Francisco. Neurociências, neurocultura e autoajuda cerebral. Interface-comunicação, saúde e educação. Vol.13 no31 Botucatu out./dez.2009.

ORTEGA, F.; VIDAL , F. Mapeamento do sujeito cerebral na cultura contemporânea. Revista Eletrônica de Comunicação Informação \& inovação em saúde. Rio de Janeiro, v. 1, n.2, p. 257-261, jul. - dez., 2007. 
VEIGA-NETO, Alfredo. Governamentalidades, neoliberalismo e educação. In: CASTELO BRANCO, Guilherme; VEIGA-NETO, Alfredo (Orgs.). Foucault, filosofia e política. Belo Horizonte: Autêntica, 2011. 